\title{
Matrine promotes liver cancer cell apoptosis by inhibiting mitophagy and PINK1/Parkin pathways
}

\author{
Runjie Wei ${ }^{1} \cdot$ Jian $\mathrm{Cao}^{2} \cdot$ Shukun Yao ${ }^{1,3}$
}

Received: 28 June 2018 /Revised: 23 August 2018 / Accepted: 2 September 2018 / Published online: 12 September 2018 (C) Cell Stress Society International 2018

\begin{abstract}
Matrine is a natural alkaloid isolated from the root and stem of the legume plant Sophora. Its anti-brol ative ahd pro-apoptotic effects on several types of cancer have been well-documented. However, the role of matrin regurating mitochondrial homeostasis, particularly mitophagy in liver cancer apoptosis, remains uncertain. The aim f our stu was to explore whether matrine promotes liver cancer cell apoptosis by modifying mitophagy. HepG2 cells vere $\mathrm{d}$ in the study and treated with different doses of matrine. Cell viability and apoptosis were determined by MTT asc- TUNE raining, western blotting, and LDH release assay. Mitophagy was monitored by immunofluorescence assay an $r^{\prime}$ vest $\mathrm{m}$ blotting. Mitochondrial function was assessed by immunofluorescence assay, ELISA, and western blotting. The results vur sudy indicated that matrine treatment dose-dependently reduced cell viability and increased the apoptotic rate of $\mathrm{HepG}_{2} \mathrm{co}$. Functional studies demonstrated that matrine treatment induced mitochondrial dysfunction and activated mitochor $\mathrm{a}_{12}$ sptosis by inhibiting protective mitophagy. Re-activation of mitophagy abolished the pro-apoptotic effects of matrine $\mathrm{n}$ HepG2 cells. Molecular investigations further confirmed that matrine regulated mitophagy via the PINK1/Park; hways. Matrine blocked the PINK1/Parkin pathways and repressed mitophagy, whereas activation of the PINK1/Parkin thway ncreased mitophagy activity and promoted HepG2 cell survival in the presence of matrine. Together, our data in ${ }^{\text {" }}$ cated at $\mathrm{n}$ atrine promoted HepG2 cell apoptosis through a novel mechanism that acted via inhibiting mitophagy and th PINK1/Pa an pathways. This finding provides new insight into the molecular mechanism of matrine for treating liver ano nd c fers a potential target to repress liver cancer progression by modulating mitophagy and the PINK1/Parkin p? vays.
\end{abstract}

Keywords Matrine $\cdot$ HepG2 cell $\cdot$ Mitoch ndrial dysfu, ction $\cdot$ Mitophagy $\cdot$ PINK/Parkin pathways

\section{Introduction}

Hepatocellular carcinoma (n) the main form of liver cancer, is the sixth most $\mathrm{m}$ cer worldwide. Notably, HCC accounts for $5.7 \%$ the overall cancer-caused mortality of elderly at and anina alone contributes to $\sim 55 \%$

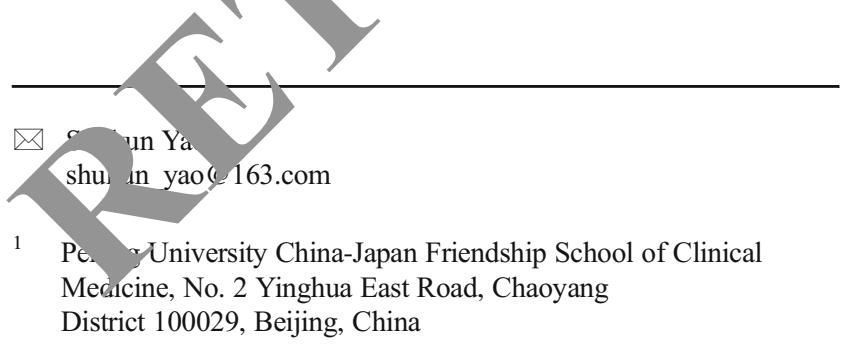

2 School of Biological Science and Medical Engineering, Beihang University, No. 37 Xueyuan Road, Haidian District 100191, Beijing, China

3 Department of Gastroenterology, China-Japan Friendship Hospital, No. 2 Yinghua East Road, Chaoyang District 100029, Beijing, China of liver cancer deaths worldwide (Wang et al. 2017). Despite great advances in the treatment of HCC, including surgery, embolization, chemotherapy, and targeted therapy (Lee and Back 2017), the 5-year survival rate remains low, ranging from $8 \%$ in developing countries to $5 \%$ in the USA or Europe (Kalyanaraman 2017). Accordingly, it is necessary to determine effective adjuvant approaches to further reduce the progression of HCC.

Matrine, a type of alkaloid, originates from the root and stem of the legume plant Sophora (Jiang et al. 2018). In a clinical setting, matrine has long been used to treat cardiovascular disorders, inflammation, hepatitis (Guo et al. 2018; Ma et al. 2018; Zhang et al. 2018), and nervous system diseases (Ligeza et al. 2017; Tobisawa et al. 2017). Several biological processes are affected by matrine, including mitochondrial function, cellular oxidative stress, autophagy, metabolic reprogramming, calcium balance, and endoplasmic reticulum stress. Recently, the anti-tumor property of matrine is verified 
by several in-depth studies in many types of human cancers. Matrine promotes human colon carcinoma cell apoptosis in a caspase-3-dependent manner (Garcia-Nino et al. 2017). In human cervical cancer, matrine represses cancer mobilization and growth (Liu et al. 2017c). Moreover, additional supplementation of matrine reduces the resistance of colorectal cancer to radiation therapy (Van Nostrand et al. 2017). Similarly, matrine treatment enhances the chemotherapeutic response in bladder cancer (Merjaneh et al. 2017). Such evidence indicates that matrine may effectively influence the development and progression of different types of cancer. However, the functional role and exact mechanisms by which matrine modulates the HCC phenotype are incompletely understood.

Mitophagy, the self-repairing system for mitochondria, removes damaged mitochondria and sustains the quantity and quality of the mitochondrial mass (Zhou et al. 2018b, Zhou et al. 2018g). In response to acute and/or chronic stress stimuli, mitophagy is executed by LC3II to engulf the damaged mitochondria (Jin et al. 2018; Shi et al. 2018). Subsequently, LC3II-formed autophagosomes cooperate with lysosomes to degrade the poorly structured mitochondria ( $\mathrm{Li}$ et al. 2018), maintaining mitochondrial homeostasis. In cardiac ischemia reperfusion, activated mitophagy removes the injured mitochondria and reduces reperfusion-mediated cardiomyocyte death (Zhou et al. 2018g). In chronic metabolic disorders, such as fatty liver disease and type 2 diabetes, upregulated mitophagy is necessary to sustain hepatocyte metarolism and mitochondrial function (Zhou et al. 2018 . In Parkinson's disease, activated mitophagy cea inflammation-mediated neuronal apoptosis (o rcia-Ru et al. 2017). These data indicate that mitophas fu ions as the pro-survival system for cells under acu $c$ and chron stimuli by preserving mitochondrial homeos isis. Because of the protective action of mitophagy on mitoch drial function and cellular viability, mitophagy is a ntentiar carget to reduce cancer progression by inducing ntito dirial dysfunction. For example, mitophagy in tion i. linked to increased gastric cancer apoptosis in ed TNE $\alpha$ (Nauta et al. 2017). In colorectal cancer, mapha $a_{c}$ suppression contributes to cancer apoptosis and vration 1, pairment (Schock et al. 2017). Based on the above in ings, we determined whether matrine

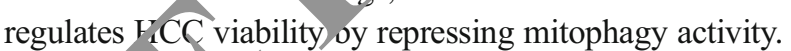

At the 1 cular evel, mitophagy is primarily regulated by thre strea regulators, namely FUNDC1, Mfn2, and D 1 in. Iotably, FUNDC1-mediated mitophagy is primarily dep Tent on hypoxia conditions (Zhou et al. 2018e, Zhou et al. $2 y, 8 \mathrm{~g}$ ). In addition, Mfn2-related mitophagy is activated in response to mitochondrial fission (Jovancevic et al. 2017). Interestingly, Parkin-mediated mitophagy is mainly triggered by mitochondrial damage (Nunez-Gomez et al. 2017). Poorly structured mitochondria with lower mitochondrial potential activate PINK1, and PINK1 recruits Parkin to accumulate on the surfaces of mitochondria, finally initiating mitophagy
(Zhao et al. 2018). More robust data concerning the causal relationship of Parkin-related mitophagy activation and cancer survival have been provided by several studies (Huang et al. 2018). However, the influence of matrine on Parkin-mediated mitophagy in HCC has not yet been comprehensively studied. Accordingly, the aim of our study was to investigate (1) whether matrine could repress HCC survival and migration, (2) whether mitophagy was inhibited by matrine and nromoted HCC mitochondrial apoptosis, and (3) whether he PINK/ Parkin pathway was required for matrine-mediatea i ophag inhibition in $\mathrm{HCC}$.

\section{Methods}

\section{Cell treatment}

HepG2 cells (Cell Ba k o e Chinese Academy of Sciences, Shanghai, China) and the $\mathrm{H} \%$ liver cancer cell line (Cell Bank of the $\mathrm{Cb}$ nese Academy of Sciences) were used to explore the role of . Thin m the liver cancer phenotype in vitro. Analyticelly pure trine, purchased from Sigma-Aldrich (Cat.No.M $>$ Ct Louis, MO, USA), was incubated with HepG2 cell for $12 \mathrm{~h}$ at different doses $(0-20 \mathrm{nM})$. To activate ^phagy, AepG2 cells were treated with FCCP $(5 \mu \mathrm{m}$, Selı $k$ Chemicals, Houston, TX, USA) for approximately $\mathrm{n} \mathrm{m}$ at $37{ }^{\circ} \mathrm{C}$ in a $5 \% \mathrm{CO}_{2}$ atmosphere. To inhibit $\mathrm{m}$ ophagy activity, 3-MA (10 mM, Selleck Chemicals, Houston, TX, USA) was added into the medium for approximately $2 \mathrm{~h}$ at $37{ }^{\circ} \mathrm{C}$ in a $5 \% \mathrm{CO}_{2}$ atmosphere (Zhu et al. 2018b).

\section{Cellular proliferation detection}

Cellular proliferation was evaluated via EdU assay. Cells were seeded onto a 6-well plate, and the Cell-Light ${ }^{\mathrm{TM}}$ EdU Apollo® 567 In Vitro Imaging Kit (Thermo Fisher Scientific Inc., Waltham, MA, USA; Catalog No. A10044) was used to observe the EdU-positive cells according to the manufacturer's instructions (Ackermann et al. 2017).

\section{Cell viability assays}

After treatment with matrine, cell viability was measured via MTT assay. For the MTT assay, cells $\left(3 \times 10^{3}\right.$ cells per well) were cultured on 96 -well plates. After $24 \mathrm{~h}$, the medium was replaced with new fresh medium containing MTT solution for an additional $2 \mathrm{~h}$ at $37{ }^{\circ} \mathrm{C}$ in a $5 \% \mathrm{CO}_{2}$ atmosphere. Subsequently, the medium was removed, and DMSO was added into the medium to dissolve the MTT solution at $37^{\circ} \mathrm{C}$ in a $5 \% \mathrm{CO}_{2}$ atmosphere for $15 \mathrm{~min}$. Finally, the plates were observed at an absorbance of $490 \mathrm{~nm}$ according to a previous study (Blackburn et al. 2017). Additionally, cell 
viability was also evaluated by analyzing the activity of caspase- 3 and caspase- 9 based on previous studies (Zhou et al. 2018d). The caspase-3 and caspase-9 activity kits were purchased from the Beyotime Institute of Biotechnology. The protein activity was estimated according to the manufacturer's instructions (Brasacchio et al. 2017).

\section{Transwell migration assay}

For Transwell migration assays, the upper chambers of 24well Transwell assay plates were seeded with $2 \times 10^{3}$ HepG2 cells in $200 \mu \mathrm{L}$ serum-free medium per well. The lower chambers were filled with $600 \mu \mathrm{L}$ medium containing $0.5 \%$ FBS (Fukumoto et al. 2018). After a 24-h incubation in a humidified incubator at $37{ }^{\circ} \mathrm{C}, 5 \% \mathrm{CO}_{2}$, cells that had migrated to the underside of the membranes were fixed and stained with $0.1 \%$ crystal violet. After washing with distilled water, pictures of each chamber were randomly taken using a $\times 200$ microscope field, and these images were used to quantify the total number of migrated cells (Pickard et al. 2017).

\section{Flow cytometric analysis}

Cellular ROS measurements were performed using the DHE probe. HepG 2 cell was incubated with $5 \mu \mathrm{M}$ DHE for $30 \mathrm{~min}$ at $37{ }^{\circ} \mathrm{C}$ in the dark. Then, cells were washed with PBS to remove free ROS probe. Subsequently, cellular ROS was bserved under the Olympus IX81 microscope and quantif d by fluorescence activated cell sorting (FACS) (Xiao et $a$. 2

\section{ELISA}

Cellular proteins were obtained after Hep i2 cells were treated with matrine. Then, the concentration or tioxidants (GSH, GPX, and SOD) and mitochondric respiratory complex were determined by ELISA using comnery ISA kits, which were purchased from the B ime It stitute of Biotechnology. The ELISA was perfor a cording to the manufacturer's instructions (Zhou ofal. 2 Pf). The absorbance of the samples was observe a $450 \mathrm{~nm}$ sing a microplate reader (BioTek, Winooski, VT, - A) according to a previous study (Du et al. 2017\%.

\section{Mit ond 'rotential and mPTP opening rate r. asu amenc}

Mitoch ndrial membrane potential was observed using JC-1 kit. HepG2 cells were incubated with the JC-1 probe for $30 \mathrm{~min}$ at $37{ }^{\circ} \mathrm{C}$ in the dark (Alghanem et al. 2017). Subsequently, cells were washed with PBS to remove the free JC-1 probe. Then, nuclei were stained with DAPI, and the mitochondrial potential was assessed under an Olympus IX81 microscope using FV10-ASW 1.7 software. The
ImageJ software was used to analyze the mitochondrial potential as described previously (Feng et al. 2017). In mPTP opening assay, cells were cultured and then incubated with calcein$\mathrm{AM} / \mathrm{CoCl}_{2}$ staining for $25 \mathrm{~min}$ at $37{ }^{\circ} \mathrm{C}$ in the dark. Subsequently, the cells were washed with PBS three times to remove the free calcein- $\mathrm{AM} / \mathrm{CoCl} 2$. The change in fluorescence intensity was measured by a fluorescence microscope according to the previous study (Chang et al. 2017). Then, the mPTP opening was measured.

\section{RNA isolation and qPCR assay}

The RNAsimple Total RNA Ki (Beyotime/nstitute of Biotechnology, China) was used to olate the total RNA in HepG2 cells. Subsequently, CD was sithesized with $1 \mu \mathrm{g}$ RNA with the Prime Scr it RT re. nt Kit. The qPCR assay was performed using a S T Green PCR Kit. The primers used in the present-ctudy $\mathrm{w}$ as follows: cadherin, F: $5^{\prime}$ CTAGTGTC AG ITTCGAAATCT-3', R: 5'-CTGT GGTACTGT' TAUCA-3'; vimentin, F: 5'-TAGT GGTTCTTGG ATTCACT-3', R: 5'-AGAG TTGTCA ATTCGG-3'; EGFR, F: 5'-GCTA CCTTTG 1GrTAGT-3', R: 5'-AGAGATACCTGATA 'GTCG')-3'; BRAF: F: 5'-TCAATGACTCCTGG AA \A-3', R: 5'-GTGATTGATCTAATGCCTAT-3'; and AP H, F: 5'-AAGTTGTGFATTAGTCA-3', R: 5'-AGAA I. GTCCTATAATCA-3'. The targeted mRNA expression was normalized to GAPDH (Boone et al. 2017).

\section{Western blotting}

Protein expression was analyzed via western blotting. Primary antibodies against the following proteins were used in the present study: caspase-9 (1:1000, Cell Signaling Technology, \#9504), pro-caspase-3 (1:1000, Abcam, \#ab13847), cleaved caspase-3 (1:1000, Abcam, \#ab49822), PARP (1:1000, Abcam, \#ab32064), Bcl2 (1:1000, Cell Signaling Technology, \#3498), survivin (1:1000, Cell Signaling Technology, \#2808), Bax (1:1000, Cell Signaling Technology, \#2772), cyclin D1 (1:1000, Abcam, \#ab16663), cyclin E (1:1000, Abcam, \#ab171535), cyt-c (1:1000; Abcam; \#ab90529), PINK1 (1:1000, Abcam, \#ab23707), cadherin (1:1000, Abcam, \#ab1416), vimentin (1:1000, Abcam, \#ab8978), CDK4 (1:1000, Abcam, \#ab137675), ATG5 (1:1000, Cell Signaling Technology, \#12994), LC3II (1:1000, Cell Signaling Technology, \#3868), LC3I (1:1000, Cell Signaling Technology, \#4599), Parkin (1:1000, Cell Signaling Technology, Inc.), and Vps34 (1:1000, Cell Signaling Technology, \#4263). GAPDH was used as a loading control, and the targeted protein expression was normalized against GAPDH (Couto et al. 2017). 

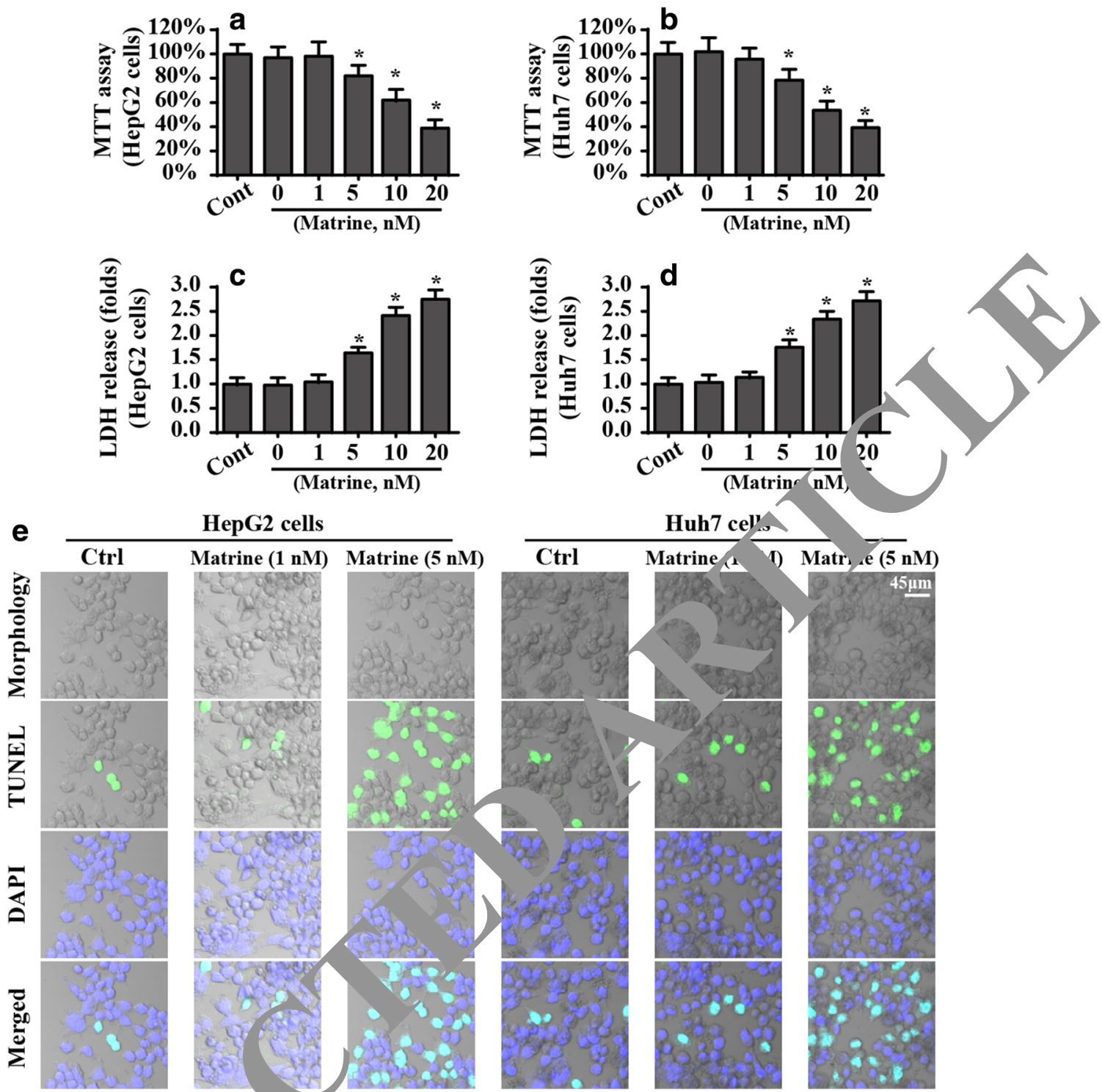

Fig. 1 Matrine induces cell death in He cells and Huh7 cells. A, B Cellular viability was evaluated via MTr $\quad$ Different doses of matrine were added into the me ${ }^{\text {r. }}$ n of Ho $\mathrm{H} 2$ cells and Huh7 cells. C, D Cell death was determine via $) \mathrm{H}$ rele $6 \mathrm{e}$. HepG2 cells and Huh7 cells were treated with dith t ations of matrine. $\mathbf{E}-\mathbf{G}$ The

\section{Parkin overey ort ion assay}

The pDC 15-Parkin vector was designed and purchased from Vigene Bio ence When the cells detached from the plates, the mo um su, -rnatant was collected. Then, the viral superna. it ientified and amplified to obtain adenovirusPark Viral transductions were performed by incubating cells with recombinant Ad-Parkin in Opti-MEM media supplemented with Lipofectamine 2000 (Thermo Fisher Scientific, Inc.) according to the manufacturer's protocol. Null vector transfection was used as the control group (Adctrl). Infection was performed for $48 \mathrm{~h}$ at $37^{\circ} \mathrm{C}$ and infection efficiency was confirmed via western blotting. number of TUNEL-positive cells was observed and used to quantify matrine-mediated cell apoptosis in HepG2 cells and Huh7 cells. H-M Western blotting was performed to analyze the proteins caspase- 3 and PARP. ${ }^{*} P<0.05$ vs. control group. Cont control group, Mat matrine group

\section{Immunofluorescence staining}

Samples were observed using a Leica DM IL LED inverted fluorescence microscope (magnification $\times 400$; Leica Microsystems, Inc.). Primary antibodies against the following proteins were used in the present study: cyt-c (1:1000; Abcam; \#ab90529), PINK1 (1:1000, Abcam, \#ab23707), cadherin (1:1000, Abcam, \#ab1416), Tom20 (mitochondrial marker, 1:1000, Abcam, \#ab186735), and LAMP1 (lysosome marker, 1:1000, Abcam, \#ab24170) (Zhou et al. 2018c). 

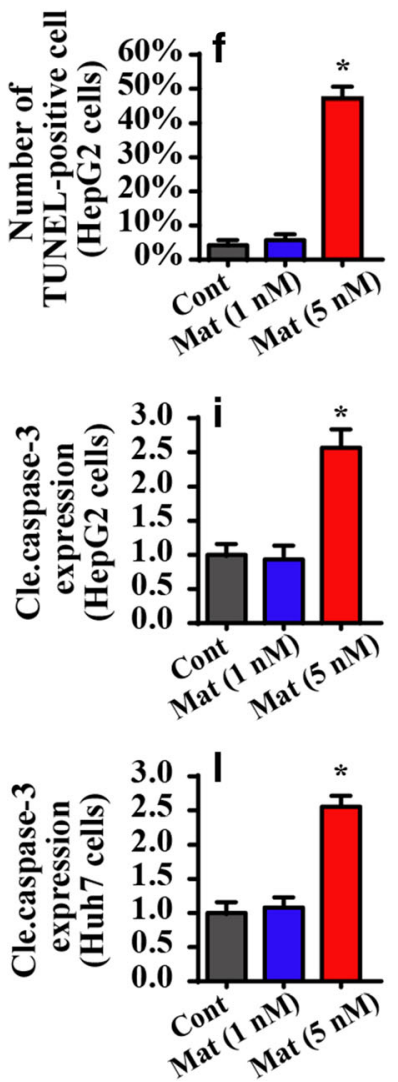

Fig. 1 continued.

\section{Statistical analysis}

Statistical processing was performed using SPSS 6.0 (SPS Inc., Chicago, IL, USA). All results in the pres nt dy were analyzed by the one-way analysis of variance, follo $d$ by Tukey's test. $P<0.05$ was considered a st tistically significant difference.

Data availability All data generate a lyzed during this study are included in this $n^{-1}$ ished irticle.

\section{Results}

\section{Matrine r,romotes $\mathrm{H}_{\text {t.pG2 }}$ cell apoptosis}

To e lish $\mathrm{t}$ deailed role of matrine in the liver cancer cell $r$ not $o$ in yitro, HepG2 cells and Huh7 cells were treated with fferent doses of matrine for approximately $12 \mathrm{~h}$. Then, an $\mathrm{M}_{1}$, assay was performed to observe cell viability. Compared to the control group, matrine dose-dependently reduced the viability of HepG2 cells and Huh7 cells (Fig. 1A, B). Similarly, the cell death ratio, evaluated by the LDH release assay, was also increased in HepG2 cells and Huh7 cells in the presence of marine (Fig. 1C, D). Notably, matrine at a dose of $1 \mu \mathrm{M}$ had no cytotoxicity on HepG2 cells, and the in Imum lethal concentration of matrine is $5 \mu \mathrm{M}$. Accordingly, $5 \mu \mathrm{M}$ matrine was used in subsequent studies. To quantify the cellular damage induced by matrine, TUNEL staining was used. Compared to the control group, matrine increased the number of TUNEL-positive cells (Fig. $1 \mathrm{E}, \mathrm{G})$. Caspase-3 activation is the molecular hallmark of apoptotic cells. Given this, we measured caspase-3 expression after matrine treatment. As shown in Fig. 1H-M, compared to the control group, $5 \mu \mathrm{M}$ matrine rather than $1 \mu \mathrm{M}$ matrine significantly increased caspase-3 expression. Additionally, caspase- 3 activation was also associated with an increase in PARP, the substrate of casapse-3 (Fig. 1H-M). Together, these data suggest that matrine has toxicity in liver cancer cells when administered at a high dose. Notably, no phenotypic differences were noted between HepG2 cells and Huh7 cells with respect to cell viability or death. HepG2 cells were used in subsequent studies.

\section{Matrine impairs HepG2 cell migration and growth}

We also determined whether matrine regulated liver cancer migration and growth. First, a transwell assay was performed to evaluate the migratory capacity of matrine-treated cells. Compared to the control group, matrine treatment clearly reduced the number of migrated cells (Fig. 2A, B). These data indicated that matrine repressed HepG2 cell mobilization. To 

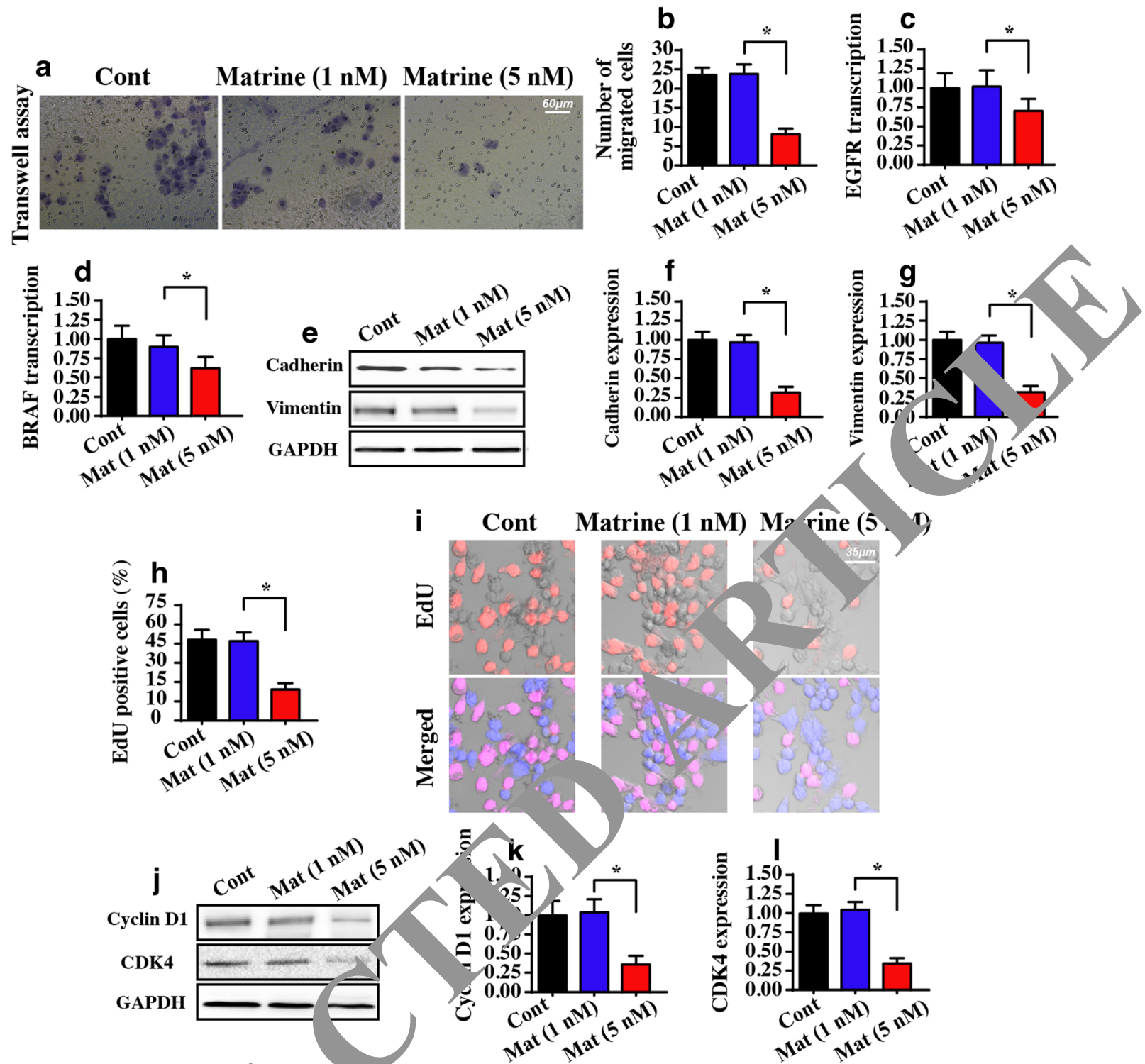

Fig. 2 Matrine regulates cell migrati nroliferation. A, B A transwell assay was used to observe the nigrau y response to HepG2 cells in the presence of matric. D The transcription of metastatic genes, including EGFR an $\mathrm{RA}$, was d,wwnregulated in response to matrine treatment. $\mathbf{E}-\mathbf{G}$ West olotmo was performed to analyze the

provide additional idence for the regulatory effects of matrine on cancer migi, son, we measured molecular expression rela to ancler metastasis. The transcription of metastatic gomos, in ding EGFR and BRAF, was also reduced in re rons to mo, rine treatment (Fig. 2C, D). Similarly, metasta. accu, such as cadherin and vimentin, were also downregula $/$ in the presence of matrine (Fig. 2E-G).

Cancer cell proliferation was also assessed with an EdU assay. As shown in Fig. 2H, I, normal liver cancer cells were $\sim 45 \%$ EdU positive, and this rate was significantly reduced with matrine treatment. The decrease in the total number of EdU-positive cells indicates a decrease in the cells at S-phase, suggesting cell cycle arrest. To validate this, western blotting protein changes of cadherin and vimentin. H, I EdU staining was applied to stain the proliferating cells at S-phase. $\mathbf{J}-\mathbf{L}$ The protein expression of cyclin D1 and CDK4 was detected via western blotting. $* P<0.05$ vs. control group. Cont control group, Mat matrine group

was performed to analyze the factors related to the cell cycle. Compared to the control, cyclin D1 and CDK4 were repressed by matrine (Fig. 2J-L). These results may indicate that the anti-proliferative effect of matrine on HepG2 cells is mediated by slowing the cell cycle in a cyclin D/E-dependent manner. Together, our data confirmed the inhibitory actions of matrine on liver cancer proliferation and migration.

\section{Matrine activates caspase-9-dependent mitochondrial apoptosis}

To determine the anti-tumor mechanism of matrine on liver cancer, we monitored mitochondrial function because the role 

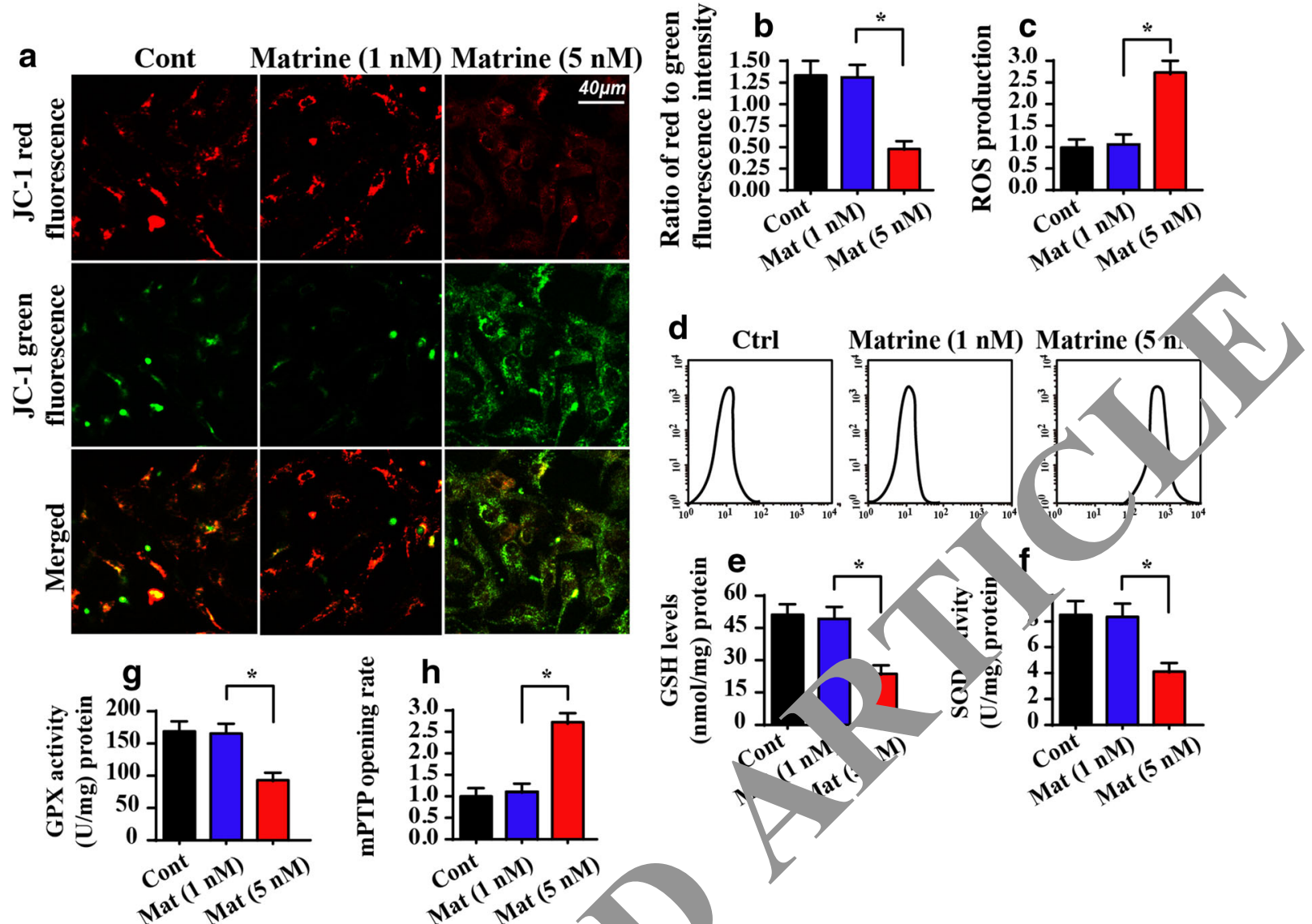

Fig. 3 Matrine treatment causes mitochondrial dysfunction. A, B $\mathrm{C}-\mathbf{1}$ staining was used to observe the mitochondrial membrane poten The red fluorescence of the JC-1 probe indicates healthy mitoch ndria ad the green fluorescence of the JC-1 probe indicates damager nitochon. al potential. C, D ROS production was measured via fl $\mathrm{W} \mathrm{C}$. metry. EG The concentration of antioxidants was measured via ELIS. H The ratio of $\mathrm{MPTP}$ opening was recorded. Matrine reatment exten .ed the

ni. $\mathrm{g}$ of the mPTP. I, J The location of cyt-c using immunofluoresce),ce. DAPI was used to stain the nucleus. Matrine promoted cyt-c leakage from mitochondria into the nucleus. $\mathbf{K}-\mathbf{Q}$ Western blotting was conducted to analyze the expression of anti- pro-apoptotic factors in matrinetreated cells. $* P<0.05$ vs. control group. Cont control group, Mat matrine group

control group (Fig. 3E-G). These data indicated that matrine mediated mitochondrial dysfunction in HepG2 cells.

Previous studies confirmed that the redox imbalance, particularly the increase in free radicals, promotes the opening of the mitochondrial permeability transition pore (mPTP) (Daiber et al. 2017). As shown in Fig. 3H, the opening time of the MPTP was significantly extended in the matrine-treated group compared to the control group. Excessive mPTP opening provides a channel for mitochondrial pro-apoptotic factors, such as cyt-c, to enter the nucleus. The immunofluorescence assay for cyt-c showed that matrine facilitated cyt-c leakage into the nucleus compared to the control group (Fig. 3I, J). This finding was further supported by western blotting, which showed a decrease in the levels of mitochondrial cyt-c (mito cyt-c), as well as a parallel increase in cytoplasmic cyt-c (cyto cyt-c) expression (Fig. 3K-Q). In addition, western blotting also demonstrated that several key proteins related to mitochondrial apoptosis, such as Bax and casapse-9 (Fig. $3 \mathrm{~K}-\mathrm{Q}$ ), were progressively upregulated in matrine-treated 

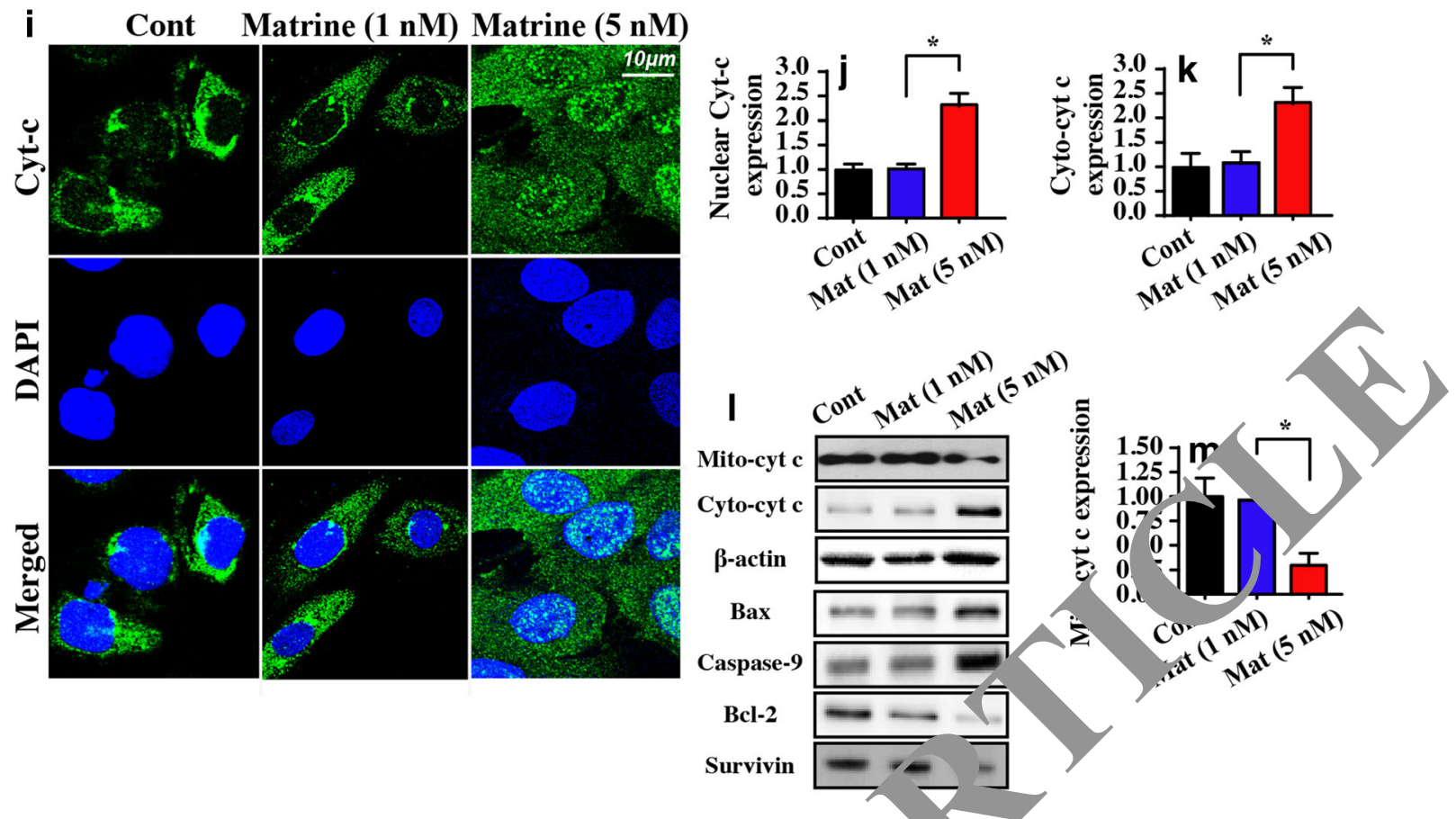

Fig. 3 continued.
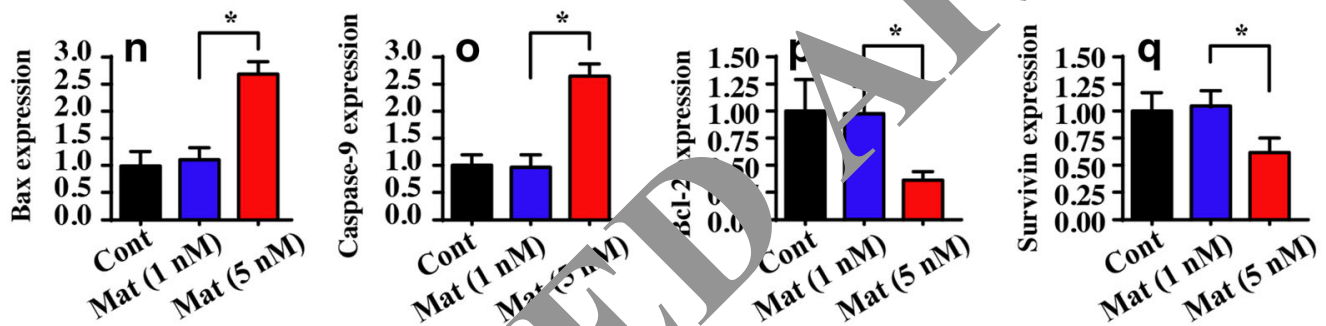

HepG2 cells. However, anti-apoptotic fartors in ding survivin and Bcl-2 were downregulate by matrine (Fig. $3 \mathrm{~K}-\mathrm{Q})$. Collectively, these data indicat that mitrine controlled cell apoptosis by activating the d. mitochondrial apoptotic pathway.

\section{Matrine induces mit hor trial nuetabolism disorder}

Mitochondria ar o centra to producing enough ATP to ensure cellular m bolism (Le Cras et al. 2017). Interestingly, cellular A).P production was strongly repressed by matrin atmel (Fig. 4A). At the molecular level, mitocho gen ATP via the mitochondrial respiratory com$r . \mathrm{H}$ wever, the activity (Fig. 4B-D) and expression (Fig. $4 \mathrm{E}-$ of the mitochondrial respiratory complex were downregulat $\mathrm{d}$ in matrine-treated cells compared to the control group. This information indicated that matrine disrupted mitochondrial energy metabolism in HepG2 cells.

To provide additional evidence for the regulatory effects of matrine on cancer mitochondrial metabolism, we measured the residual glucose in the medium. As shown in Fig. 4I, compared to the control group, matrine treatment increased

the concentration of glucose in the medium, indicative of the decline in glucose uptake. Moreover, the increase in glucose in the medium occurred along with a decrease in the levels of lactic acid in the medium supplemented with matrine (Fig. 4J), indicating the termination of cancer cell mitochondrial glucose metabolism. Together, our data demonstrated that mitochondrial energy metabolism was negatively affected by matrine.

\section{Matrine regulates mitochondrial homeostasis by repressing mitophagy}

Previous studies have reported that mitophagy is a defensive mechanism to support cancer survival in response to acute and/or chronic stress. Activated mitophagy can remove damaged mitochondria and sustains mitochondrial homeostasis. Given this, we questioned whether mitophagy is involved in matrine-mediated HepG2 cell mitochondrial damage. First, mitophagy was detected using an immunofluorescence assay. As shown in Fig. 5A, B, there was tight cooperation between mitochondria and the lysosome in the control group, suggesting mitophagy activation. However, matrine treatment 

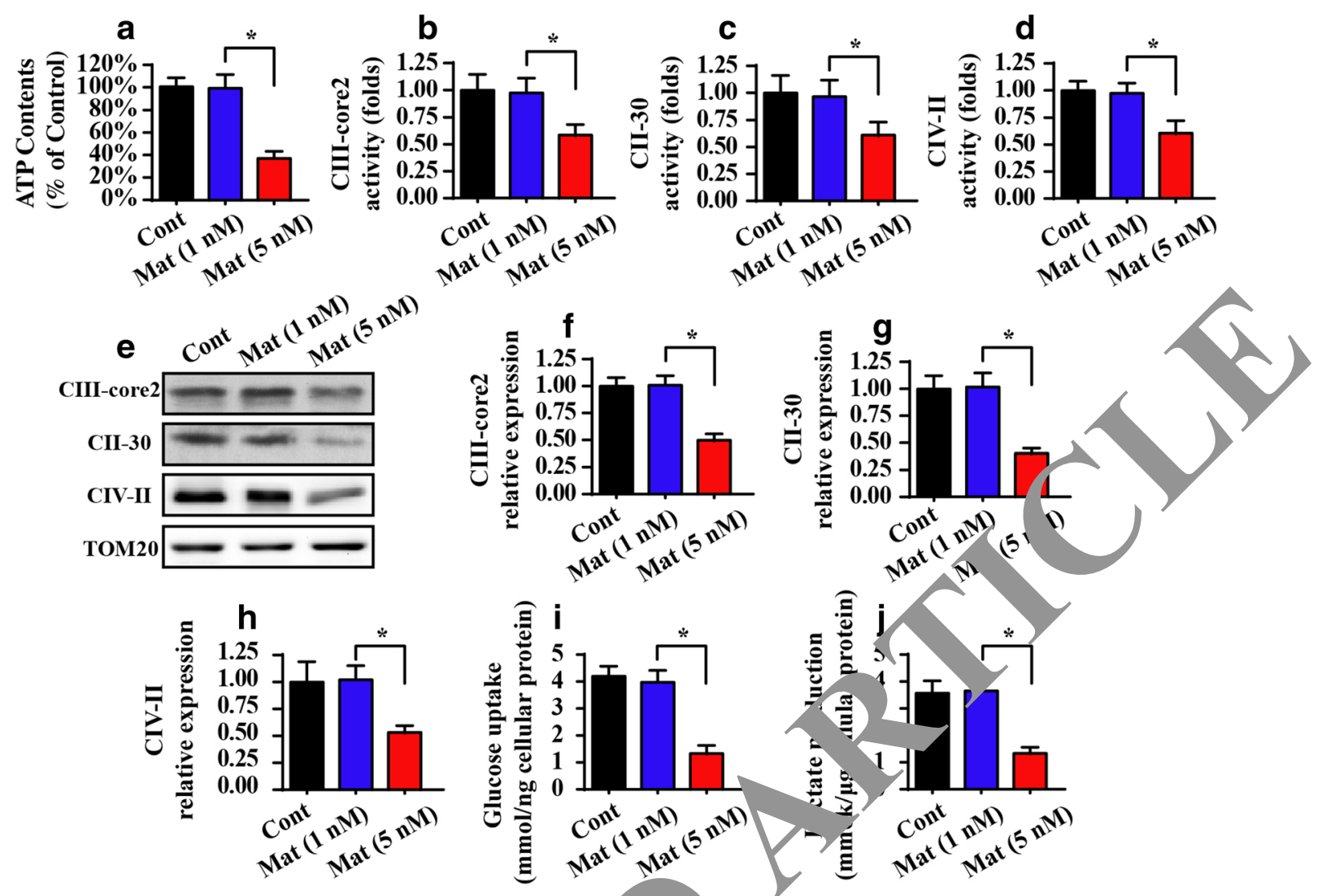

Fig. 4 Matrine modulates mitochondrial energy metabolism. A Cellular ATP production was measured via ELISA. B-D The activity of the mitochondrial respiratory complex via ELISA assay. E-H Western blotting was performed to analyze the protein expression $f$ th $\mathrm{s}$

interrupted the binding of mitochondria to lysose s, indica, ing mitophagy inhibition (Fig. 5A, B). Furthermoro vestern blotting was performed to quantitatively valuate mito, phagy activity. As shown in Fig. 5C-H, com ared to the control group, matrine treatment reduced LC3I nrescon and decreased the LC3II/LC3I ratio. Mor or mitochondrial LC3II expression was also downregulated y sponse to matrine administration. Additicia , milochondrial autophagy markers, such as ATE. nd 24 , were also reduced in matrine-treated getrs co ared to the control group. Together, these at dicated hat matrine suppressed the activity of mito hagy in $\mathrm{CC}$.

To val ate whether mitophagy is involved in matrinemediated his chonc ial damage, loss- and gain-of-function assav 10 nitop $y$ were performed. FCCP, a type of mitophagy as ist added to matrine-treated cells to induce mitophagy. In co ' רst, 3-MA, a blocker of mitophagy, was administered to the con ol group, which was used as the negative control group. Then, mitochondrial damage was assessed with a caspase-9 activity assay. As shown in Fig. 5I, inhibition of mitophagy occurred in the control group, and caspase-9 activity was increased, similar to the results obtained with matrine. However, matrineincreased caspase- 9 activity was strongly inhibited by FCCP treatment. These data indicated that reactivation of mitophagy protected mitochondria against matrine-mediated damage in HepG2 cells. These findings were further verified via the LDH release assay (Fig. 5J), which is the early hallmark of cell death. Matrine-mediated LDH release was repressed by FCCP. Taken together, our data confirmed that matrine modulates HepG2 cell mitochondrial damage by repressing mitophagy activity.

\section{Matrine represses mitophagy via the PINK1/Parkin pathway}

Previous studies suggested that cancer mitophagy is primarily controlled by the PINK1/Parkin pathway (Yan et al. 2018; Zhao et al. 2018). Accordingly, we asked whether the PINK1/Parkin pathway is involved in matrine-related mitophagy. Western blotting assays demonstrated that the levels of both PINK1 and Parkin expression were mostly downregulated in matrine-treated cells (Fig. 6A-C) compared to the control group. Similarly, the immunofluorescence results of PINK1 and Parkin exhibited a parallel downregulation of PINK and Parkin in response to matrine treatment (Fig. 6D-F). The above data demonstrated the inhibitory action of matrine on the PINK1/Parkin pathway. 
Fig. 5 Matrine represses protective mitophagy. A, B Mitophagy activity was monitored via

immunofluorescence.

Mitochondria were stained with Tom20, and lysosomes were stained with Lamp1. FCCP, an activator of mitophagy, was added into the matrine-treated cells to reactivate mitophagy. 3$\mathrm{MA}$, an inhibitor of mitophagy, was used in the control group, which was considered the negative control group. Then, the fusion of mitochondria and lysosomes indicates mitophagy, which was recorded. $\mathbf{C}-\mathbf{H}$ Western blotting was performed to analyze the proteins related to mitophagy. FCCP, an activator of mitophagy, was added into the matrine-treated cells to reactivate mitophagy. 3-MA, an inhibitor of mitophagy, was used in the control group, which was the negative control group. I Caspase-9 activity was measured to reflect the role of mitophagy in mitochondrial apoptosis. J An LDH release assay was used to analyze the contribution of mitophagy to cell death. $* P<0.05$ vs. control group. Cont control group, Mat matrine group

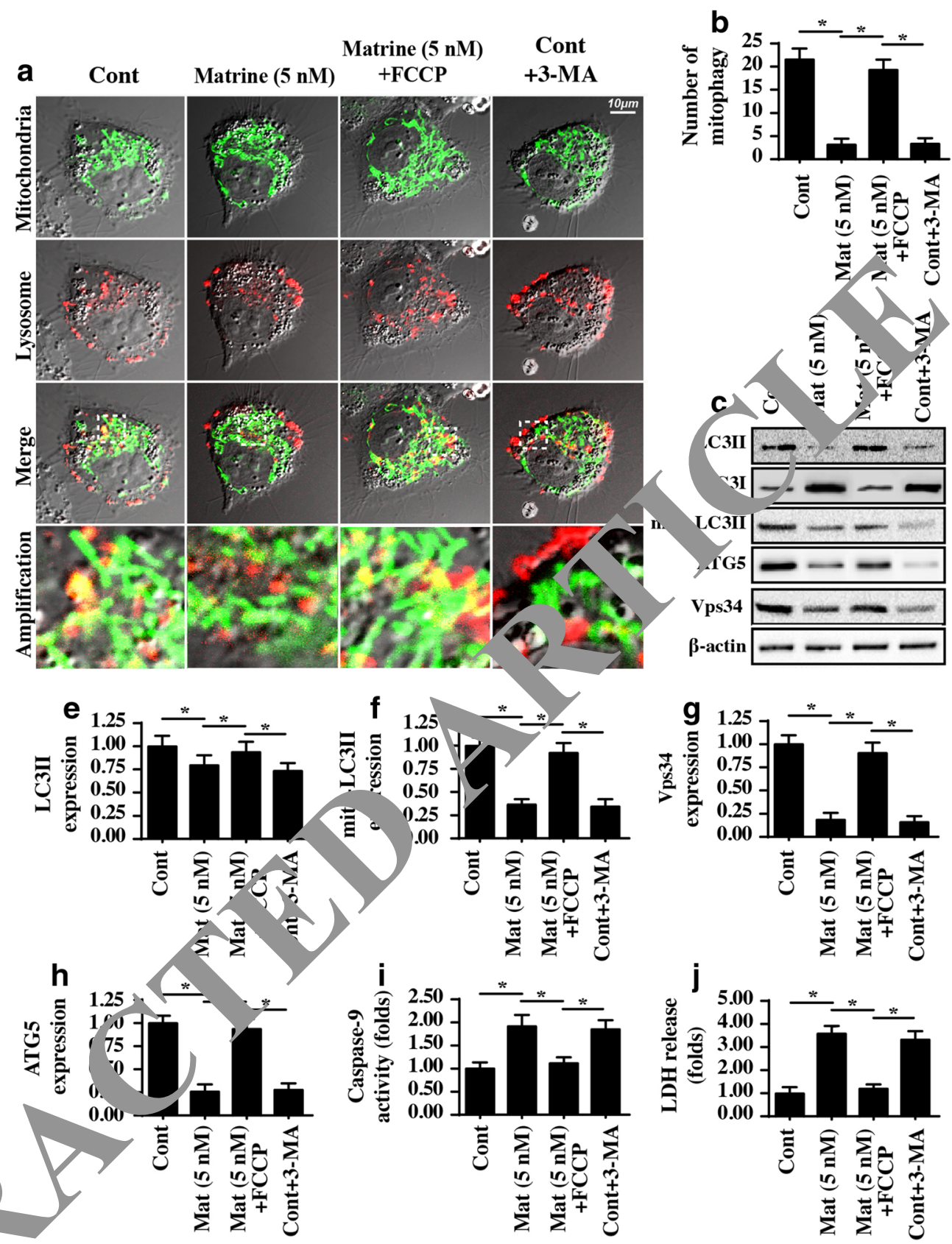

PINK1/Parkin pathway is also involved in HepG2 cell migration and growth

Finally, we explored the role of the PINK1/Parkin pathway in HepG2 cell migration and growth. First, a transwell assay demonstrated that matrine-inhibited cell mobilization was reversed by Parkin overexpression (Fig. 7A, B). Additionally, the transcription of migratory factors such as cadherin and vimentin was also downregulated in response to matrine treatment and was returned to near-normal levels after the overexpression of Parkin (Fig. 7C, D). These data indicated that reactivation of the PINK1/Parkin pathway negated the inhibitory effects of matrine on HepG2 cell migration. 



Fig. 6 Matrine regulates mitophagy via PINK1/Parkin pathways. A-C The activity of the PINK1/Parkin pathways was measured using western blotting. D-F The immunofluorescence assay for PINK1 and Parkin. G, H Adenovirus-overexpressed Parkin (Ad-Parkin) was transfected into HepG2 cells, and the overexpression efficiency was confirmed with western blotting. I, J Mitophagy was evaluated using an immunofluorescence assay. Ad-Parkin was transfected into HepG2 cells in the presence of matrine. $* P<0.05$ vs. control group. Cont control group, Mat matrine group 


\section{a}
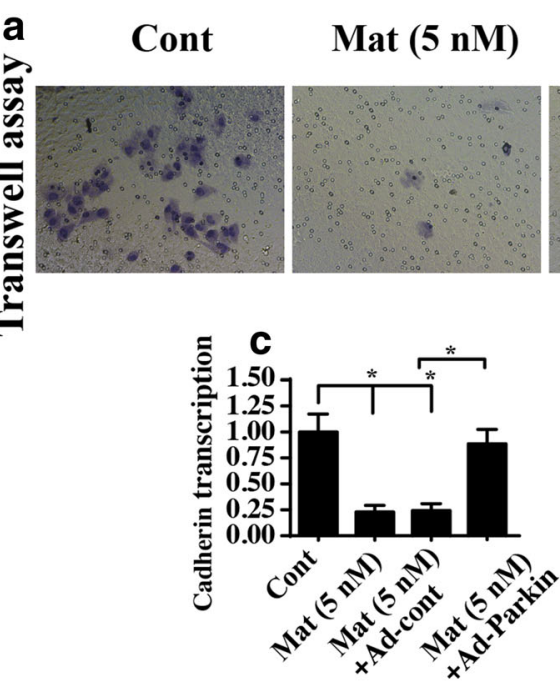

Mat (5 nM)

+Ad-cont
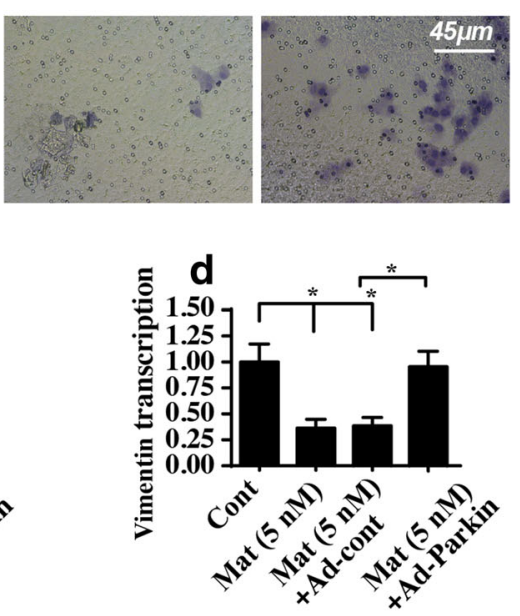

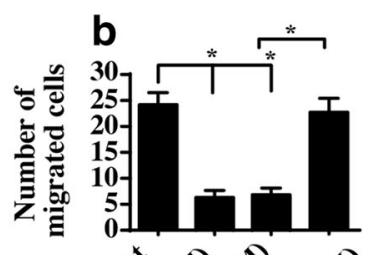

00<smiles>C1=C=C=CC=C=1</smiles>

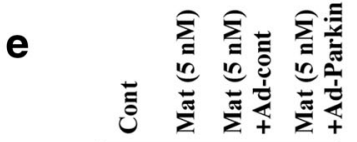

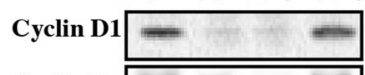

Cyclin E

GAPDH
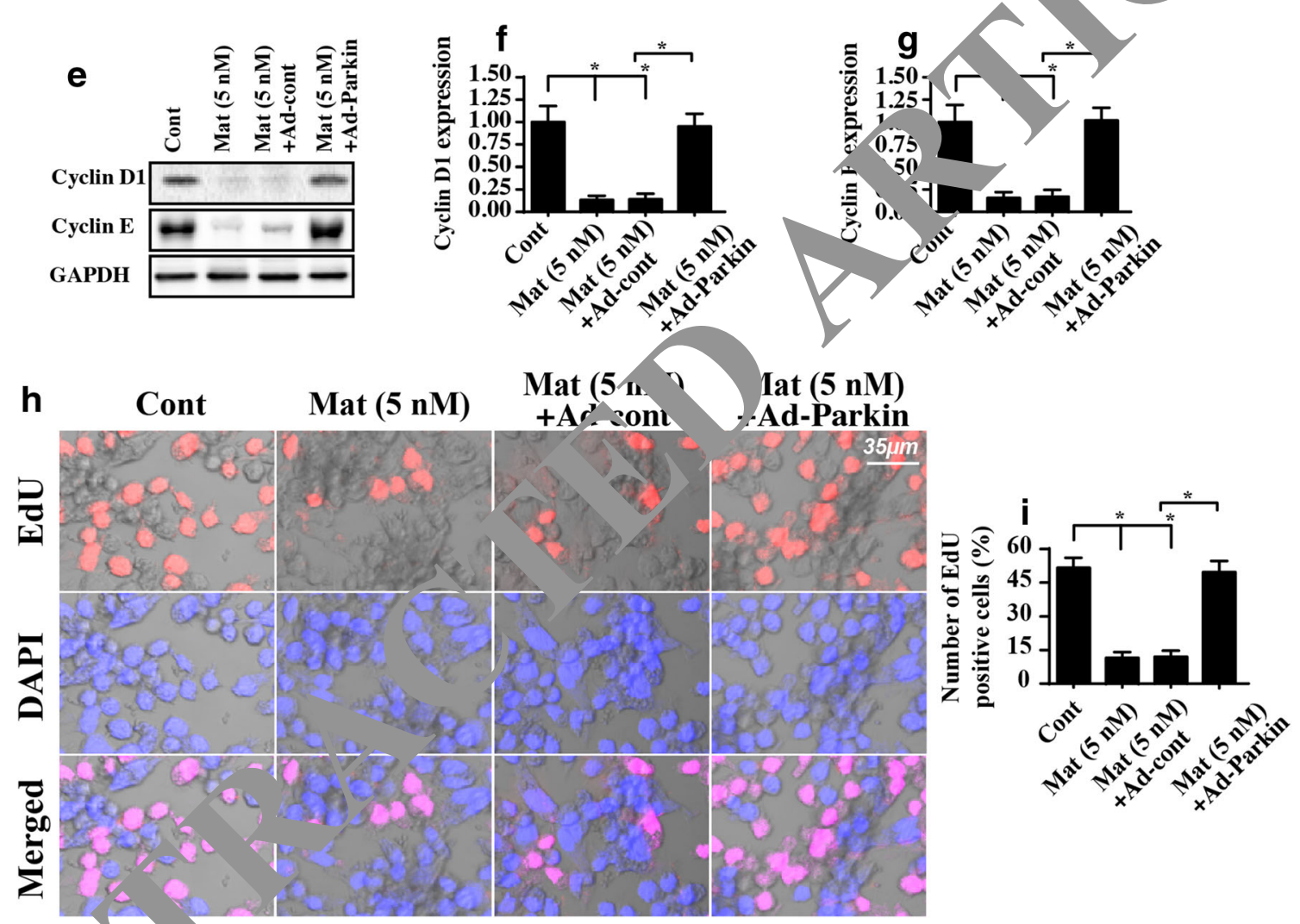

Fig. 7 PINK Aarkin pa ays are also involved in HepG2 cell migration d proliferation. A, B The migratory response of HepG2 cells treatea 1 matr $\mathrm{ce}$ or transfected with Ad-Parkin was estimated via tr vell as $\mathbf{C}, \mathbf{D}$ The transcription of metastatic factors, such as cr herit and vil ientin. HepG2 cells were treated with matrine or

$\mathrm{Re}_{\text {s }}$ ing cellular proliferation, the expression of cyclin D1 and $\mathrm{E}$ was downregulated in matrine-treated cells and upregulated in Parkin-overexpressing cells (Fig. 7E-G). Moreover, the EdU assay demonstrated that matrine reduced and Parkin overexpression reversed the number of EdU-positive cells (Fig. 7H, I). Together, these data suggested that matrine regulated liver cancer growth via the PINK1/Parkin pathway. transfected with Ad-Parkin. E-G Western blotting was used to analyze the protein expression of cyclin D1 and cyclin E. H, I EdU assay for cell proliferation. HepG2 cells were treated with matrine or transfected with Ad-Parkin; then, the number of EdU-positive cells was recorded. $* P<0.05$ vs. control group. Cont control group, Mat matrine group

\section{Discussion}

In the present study, our data found that matrine regulated mitochondrial function by repressing mitophagy. At the molecular levels, matrine administration interrupted the cooperation between mitochondria and lysosomes, reducing mitophagy activity. However, reactivation of mitophagy 
abrogated the pro-apoptotic effects of matrine on HepG2 cells. This experimental evidence substantiated the sufficiency of matrine to repress mitophagy, as well as the necessity of mitophagy for liver cancer survival. To our knowledge, this is the first investigation to identify matrine as an upstream mediator of mitophagy in liver cancer. This finding was similar to previous study. For example, in human acute lymphoblastic leukemia, matrine augments ROS production and causes mitochondrial swelling (Liu et al. 2017b). Additionally, matrine suppresses survivin signaling to promote mitochondrial apoptosis in non-small cell lung cancer (Perdiz et al. 2017). More importantly, in liver cancer, matrine activates Bid-mediated mitochondrial apoptosis in vivo and in vitro (Liu et al. 2017a). These data confirm that mitochondria are the potential target of matrine for regulating cancer viability.

Notably, previous studies found that mitophagy activation provides a pro-survival advantage for several types of cancer. In gastric cancer, although $\mathrm{TNF} \alpha$-based therapy reduces cancer viability and increases the apoptotic index, it also activates mitophagy (Zhang et al. 2016). Augmented mitophagy degrades the damaged mitochondria and prevents the amplification of apoptotic signaling. Additionally, in human cervical cancer, activated mitophagy promotes cancer survival and is involved in a tumor cell's ability to escape programmed cell death (Sarkar et al. 2017). Consistent with this finding, activated mitophagy also promotes migration and adhesion in endometriosis and liver cancer (Shi et al. 2018; Zhao et al. 2018). Given these observations, previous studies prop that mitophagy may play a key role in tumor escar and tum therapy resistance. Our data also provide evid nce further validate this hypothesis. Based on these dra, the inhib. of of mitophagy is of utmost importance $w$ en designing anticancer therapies in combination with o mothe apy. More importantly, our data provide an $\mathrm{cr}$ and crective method to block mitophagy, namely matrin. Aministration of matrine inhibited mitoph a. activily and further promoted mitochondrial malfu tion evidenced by increased caspase-9 activity and augmented apoptotic ratio. Therefore, our ros in Hep $s 2$ cells lay the foundation for a detailed study of th olecular mechanisms of liver cancer apoptosis nanagement and regulation. Furthermore, we provide new that how that mitophagy inhibition is responsibl the at -suppressive action of matrine.

It th molecular level, mitophagy is primarily regulated by FU C1, Mffn2, and Parkin. FUNDC1, the mitophagy receptor exp ussed on the outer membrane of mitochondria, is preferentially activated by hypoxia stimulus. In ischemiachallenged tissues, such as the heart, FUNDC1 is activated and protects mitochondria against stress-evoked apoptosis (Zhou et al. 2018e, Zhou et al. 2018g). Mfn2-mediated mitophagy is primarily triggered along with mitochondrial fission. In gastric cancer and pancreatic cancer, Mfn2- mediated mitophagy promotes cancer cell survival by sustaining mitochondrial function and structure. Parkin is mainly activated in response to a reduction in mitochondrial potential (Fuhrmann and Brune 2017). The mitochondrial potential collapse causes PINK1 upregulation, and this enhances Parkin expression. Elevated Parkin levels promote the fusion between mitochondria and lysosomes, contributing to the removal of damaged mitochondria (Rossello and Yellon 2017). In this present study, we found that PIN $1 /$ Parkinmediated mitophagy was inhibited by matrine. weve; overexpression of PINK1 could reactivate mitop $\mathrm{v}$ in matrine-treated cells and reduce caspase- -5 tivation and cellular apoptosis. This comprehensivel, uemo ate that the PINK1/Parkin pathway is requ ed for ma/rine-related mitophagy. However, more stydies re needed to determine whether matrine has a role regurwning mitophagy via FUNDC1 and/or Mfn2.

Together, our dath ated that matrine can reduce HepG2 cell viabilitw the mig cy response, and proliferation in vitro. Mecha istic. ly, matrine suppresses mitophagy activity by downreg mitochondrial dy Inction and activating caspase-9dependen 1 hondrial apoptosis in HepG2 cells. These findings provide new insights into the mechanisms of and strategi $s$ for regulating the progression of liver cancer.

'utho contribution CJ and SKY conceived the research; RJW, CJ, and performed the experiments; all authors participated in discussing and revising the manuscript.

Funding This study was funded in full by the Leap-forward Development Program for Beijing Biopharmaceutical Industry (G20), grant number Z171100001717008.

\section{References}

Ackermann M, Kim YO, Wagner WL, Schuppan D, Valenzuela CD, Mentzer SJ, Kreuz S, Stiller D, Wollin L, Konerding MA (2017) Effects of nintedanib on the microvascular architecture in a lung fibrosis model. Angiogenesis 20:359-372. https://doi.org/10.1007/ s10456-017-9543-Z

Alghanem AF, Wilkinson EL, Emmett MS, Aljasir MA, Holmes K, Rothermel BA, Simms VA, Heath VL, Cross MJ (2017) RCAN1.4 regulates VEGFR-2 internalisation, cell polarity and migration in human microvascular endothelial cells. Angiogenesis 20: 341-358. https://doi.org/10.1007/s10456-017-9542-0

Blackburn NJR, Vulesevic B, McNeill B, Cimenci CE, Ahmadi A, Gonzalez-Gomez M, Ostojic A, Zhong Z, Brownlee M, Beisswenger PJ, Milne RW, Suuronen EJ (2017) Methylglyoxalderived advanced glycation end products contribute to negative cardiac remodeling and dysfunction post-myocardial infarction. Basic Res Cardiol 112:57. https://doi.org/10.1007/s00395-017-0646-x

Boone CHT, Grove RA, Adamcova D, Seravalli J, Adamec J (2017) Oxidative stress, metabolomics profiling, and mechanism of local anesthetic induced cell death in yeast. Redox Biol 12:139-149. https://doi.org/10.1016/j.redox.2017.01.025 
Brasacchio D, Alsop AE, Noori T, Lufti M, Iyer S, Simpson KJ, Bird PI, Kluck RM, Johnstone RW, Trapani JA (2017) Epigenetic control of mitochondrial cell death through PACS1-mediated regulation of BAX/BAK oligomerization. Cell Death Differ 24:961-970. https:// doi.org/10.1038/cdd.2016.119

Chang SH, Yeh YH, Lee JL, Hsu YJ, Kuo CT, Chen WJ (2017) Transforming growth factor-beta-mediated CD44/STAT3 signaling contributes to the development of atrial fibrosis and fibrillation. Basic Res Cardiol 112:58. https://doi.org/10.1007/s00395-0170647-9

Couto JA, Ayturk UM, Konczyk DJ, Goss JA, Huang AY, Hann S, Reeve JL, Liang MG, Bischoff J, Warman ML, Greene AK (2017) A somatic GNA11 mutation is associated with extremity capillary malformation and overgrowth. Angiogenesis 20:303-306. https://doi. org/10.1007/s10456-016-9538-1

Daiber A, Oelze M, Steven S, Kroller-Schon S, Munzel T (2017) Taking up the cudgels for the traditional reactive oxygen and nitrogen species detection assays and their use in the cardiovascular system. Redox Biol 12:35-49. https://doi.org/10.1016/j.redox.2017.02.001

Du GQ et al (2017) Targeted myocardial delivery of GDF11 gene rejuvenates the aged mouse heart and enhances myocardial regeneration after ischemia-reperfusion injury. Basic Res Cardiol 112:7. https:// doi.org/10.1007/s00395-016-0593-y

Feng D et al. (2017) Pre-ischemia melatonin treatment alleviated acute neuronal injury after ischemic stroke by inhibiting endoplasmic reticulum stress-dependent autophagy via PERK and IRE1 signalings. J Pineal Res 62. doi:https://oi.org/10.1111/jpi.12395

Fuhrmann DC, Brune B (2017) Mitochondrial composition and function under the control of hypoxia. Redox Biol 12:208-215. https://doi. org/10.1016/j.redox.2017.02.012

Fukumoto M, Kondo K, Uni K, Ishiguro T, Hayashi M, Ueda S, Mori I, Niimi K, Tashiro F, Miyazaki S, Miyazaki JI, Inagaki S, Furuyama T (2018) Tip-cell behavior is regulated by transcription factor FoxOT under hypoxic conditions in developing mouse reti $\mathrm{ad}$ Angiogenesis 21:203-214. https://doi.org/10.1007/s1045 017 9588-z

Garcia-Nino WR et al (2017) Cardioprotective kinase signaling subsarcolemmal and interfibrillar mitochondria is diated by caveolar structures. Basic Res Cardiol 112:15 hitps:/ $/$ org/10. 1007/s00395-017-0607-4

Garcia-Ruiz JM et al (2017) Bloodless reperfus in with the oxygen carrier HBOC-201 in acute myocardial infarc a nove platform for cardioprotective probes delivery. Basic Res 112:17. https:// doi.org/10.1007/s00395-017-0605-

Guo S, Gao C, Xiao W, Zhang J, Qu Y, Li T, Y J18) Matrine protects cardiomyocytes from isc $\mathrm{a} /$ repe fusion injury by regulating HSP70 expression vi activi on of re JAK2/STAT3 pathway. Shock:1. https://doi org $1 f_{0}, 0000000000001108$

Huang CY, Kuo WW Ho TJ, C. g. SF, Pai PY, Lin JY, Lin DY, Kuo $\mathrm{CH}$, Huang Cr 18) Rab9), dependent autophagy is required for the IGF-IIR trigger nitophagy to eliminate damaged mitochondria. J Cell Physiol 2, s:7080-7091. https://doi.org/10.1002/jcp. 2634

Jiang JH, P1 Tin H Yang F, Cai JY (2018) Chinese herb medicine II. ne in apoptosis in human esophageal squamous cancer KY F_-150 ells through increasing reactive oxygen species and nibitus mitochondrial function. Pathol Res Pract 214:691-699. h. "/doi.org/10.1016/j.prp.2018.03.015

Jin Q, LA R, Hu N, Xin T, Zhu P, Hu S, Ma S, Zhu H, Ren J, Zhou H (2018) DUSP1 alleviates cardiac ischemia/reperfusion injury by suppressing the Mff-required mitochondrial fission and Bnip3related mitophagy via the JNK pathways. Redox Biol 14:576-587. https://doi.org/10.1016/j.redox.2017.11.004

Jovancevic N, Dendorfer A, Matzkies M, Kovarova M, Heckmann JC, Osterloh M, Boehm M, Weber L, Nguemo F, Semmler J, Hescheler J, Milting H, Schleicher E, Gelis L, Hatt H (2017) Medium-chain fatty acids modulate myocardial function via a cardiac odorant receptor. Basic Res Cardiol 112:13. https://doi.org/10.1007/s00395017-0600-y

Kalyanaraman B (2017) Teaching the basics of cancer metabolism: developing antitumor strategies by exploiting the differences between normal and cancer cell metabolism. Redox Biol 12:833-842. https:// doi.org/10.1016/j.redox.2017.04.018

Le Cras TD, Mobberley-Schuman PS, Broering M, Fei L, Trenor CC, 3rd, Adams DM (2017) Angiopoietins as serum biomarkers for lymphatic anomalies. Angiogenesis 20:163-173. doi:ht+ps://doi. org/10.1007/s10456-016-9537-2

Lee HY, Back K (2017) Melatonin is required for $\mathrm{H} 2$ mediated defense signaling through MAPKKK3 an $>\mathrm{XI} 1 \mathrm{in}$ Arabidopsis thaliana. J Pineal Res 62. doi: $\mathrm{h}^{+}$ps://doi.org/ . 111/ jpi.12379

Li R, Xin T, Li D, Wang C, Zhu H, Zhou H (2) 8) A pev. ic effect of Sirtuin 3 on ameliorating nonalcoholi fatty liver dis ase: the role of the ERK-CREB pathway and Bnip mediated mitophagy. Redox Biol 18:229-243. https://doi.or /10.1 /i.redo x.2018.07.011

Ligeza J, Marona P, Gach N, Lipert L Miekus 1, Wilk W, Jaszczynski J, Stelmach A, Loboda A. Julak J, L ricki W, Rys J, Jura J (2017) MCPIP1 contributes to cell rena cell carcinomas development. Angiogenesis 20:325-34u tps://doi.org/10.1007/s10456-0179540-2

Liu D, Zeng X, X, Tehta JL, Wang X (2017a) Role of NLRP3 inflammason thogenesis of cardiovascular diseases. Basic Res Cara 113:5. https://doi.org/10.1007/s00395-017$0663-$

Liu Z, Gan L, Sun C (2017b) Melatonin promotes circadian rhythm-1duced proliferation through Clock/histone deacetylase 3/ c-Myc in -raction in mouse adipose tissue. J Pineal Res 62. doi: ps://doi.org/10.1111/jpi.12383

Liu Z, Jan L, Xu Y, Luo D, Ren Q, Wu S, Sun C (2017c) Melatonin a leviates inflammasome-induced pyroptosis through inhibiting NFkappaB/GSDMD signal in mice adipose tissue. J Pineal Res 63. doi: https://doi.org/10.1111/jpi.12414

Ma J, Ma S, Yin C, Wu H (2018) Matrine reduces susceptibility to postinfarct atrial fibrillation in rats due to antifibrotic properties. J Cardiovasc Electrophysiol 29:616-627. https://doi.org/10.1111/jce. 13448

Merjaneh M, Langlois A, Larochelle S, Cloutier CB, Ricard-Blum S, Moulin VJ (2017) Pro-angiogenic capacities of microvesicles produced by skin wound myofibroblasts. Angiogenesis 20:385-398. https://doi.org/10.1007/s10456-017-9554-9

Nauta TD, van den Broek M, Gibbs S, van der Pouw-Kraan TC, Oudejans CB, van Hinsbergh VW, Koolwijk P (2017) Identification of HIF-2alpha-regulated genes that play a role in human microvascular endothelial sprouting during prolonged hypoxia in vitro. Angiogenesis 20:39-54. https://doi.org/10.1007/s10456016-9527-4

Nunez-Gomez E, Pericacho M, Ollauri-Ibanez C, Bernabeu C, LopezNovoa JM (2017) The role of endoglin in post-ischemic revascularization. Angiogenesis 20:1-24. https://doi.org/10.1007/s10456-0169535-4

Perdiz D, Lorin S, Leroy-Gori I, Pous C (2017) Stress-induced hyperacetylation of microtubule enhances mitochondrial fission and modulates the phosphorylation of Drp1 at (616)Ser. Cell Signal 39:32-43. https://doi.org/10.1016/j.cellsig.2017.07.020

Pickard JM, Burke N, Davidson SM, Yellon DM (2017) Intrinsic cardiac ganglia and acetylcholine are important in the mechanism of ischaemic preconditioning. Basic Res Cardiol 112:11. https://doi.org/10. 1007/s00395-017-0601-x

Rossello X, Yellon DM (2017) The RISK pathway and beyond. Basic Res Cardiol 113:2. https://doi.org/10.1007/s00395-017-0662-x

Sarkar C, Ganju RK, Pompili VJ, Chakroborty D (2017) Enhanced peripheral dopamine impairs post-ischemic healing by suppressing 
angiotensin receptor type 1 expression in endothelial cells and inhibiting angiogenesis. Angiogenesis 20:97-107. https://doi.org/ 10.1007/s10456-016-9531-8

Schock SN, Chandra NV, Sun Y, Irie T, Kitagawa Y, Gotoh B, Coscoy L, Winoto A (2017) Induction of necroptotic cell death by viral activation of the RIG-I or STING pathway. Cell Death Differ 24:615-625. https://doi.org/10.1038/cdd.2016.153

Shi C, Cai Y, Li Y, Li Y, Hu N, Ma S, Hu S, Zhu P, Wang W, Zhou H (2018) Yap promotes hepatocellular carcinoma metastasis and mobilization via governing cofilin/F-actin/lamellipodium axis by regulation of JNK/Bnip3/SERCA/CaMKII pathways. Redox Biol 14: 59-71. https://doi.org/10.1016/j.redox.2017.08.013

Tobisawa T, Yano T, Tanno M, Miki T, Kuno A, Kimura Y, Ishikawa S, Kouzu H, Nishizawa K, Yoshida H, Miura T (2017) Insufficient activation of Akt upon reperfusion because of its novel modification by reduced PP2A-B55alpha contributes to enlargement of infarct size by chronic kidney disease. Basic Res Cardiol 112:31. https:// doi.org/10.1007/s00395-017-0621-6

Van Nostrand JL, Bowen ME, Vogel H, Barna M, Attardi LD (2017) The p53 family members have distinct roles during mammalian embryonic development. Cell Death Differ 24:575-579. https://doi.org/10. 1038/cdd.2016.128

Wang K, Gan TY, Li N, Liu CY, Zhou LY, Gao JN, Chen C, Yan KW, Ponnusamy M, Zhang YH, Li PF (2017) Circular RNA mediates cardiomyocyte death via miRNA-dependent upregulation of MTP18 expression. Cell Death Differ 24:1111-1120. https://doi. org/10.1038/cdd.2017.61

Xiao L, Xu X, Zhang F, Wang M, Xu Y, Tang D, Wang J, Qin Y, Liu Y, Tang C, He L, Greka A, Zhou Z, Liu F, Dong Z, Sun L (2017) The mitochondria-targeted antioxidant MitoQ ameliorated tubular injury mediated by mitophagy in diabetic kidney disease via Nrf2/PINK1. Redox Biol 11:297-311. https://doi.org/10.1016/j.redox.2016.12. 022

Yan H, Xiao F, Zou J, Qiu C, Sun W, Gu M, Zhang L (2018) NR A induced increase in the sensitivity of a human gastric cance ine to TNFalpha-mediated apoptosis is associated with the inhibi JNK/Parkin-dependent mitophagy. Int J Oncol $2: 367-3$ https://doi.org/10.3892/ijo.2017.4216

Zhang Y, Zhou H, Wu W, Shi C, Hu S, Yin T, Ma O, Han 1 , ang Y, Tian F, Chen Y (2016) Liraglutide protects cardrac micro wcular endothelial cells against hypoxia/reoxyger tion injury through the suppression of the SR-Ca(2+)-XO-ROS a via acti vation of the GLP-1R/PI3K/Akt/survivin pathways. Fre 1: Biol Med 95: 278-292. https://doi.org/10.1016/j.1 dhiomed.2016.03.035

Zhang Y, Yang X, Qiu C, Liu F, Liu P, Li 1 L, o) Matrine suppresses AGE-induced HAEC injv $\mathrm{v}$ inhib ting ROS-mediated NRLP3 inflammasome activati ఛ. Eu J Phar Aacol 822:207-211. https:// doi.org/10.1016/j.ejnhar.
Zhao Q, Ye M, Yang W, Wang M, Li M, Gu C, Zhao L, Zhang Z, Han W, Fan W, Meng Y (2018) Effect of Mst1 on endometriosis apoptosis and migration: role of Drp1-related mitochondrial fission and Parkin-required mitophagy. Cell Physiol Biochem 45:1172-1190. https://doi.org/10.1159/000487450

Zhou H et al. (2018a) Effects of melatonin on fatty liver disease: the role of NR4A1/DNA-PKcs/p53 pathway, mitochondrial fission, and mitophagy. J Pineal Res 64. doi:https://doi.org/10.1111/jpi.12450

Zhou H, Ma Q, Zhu P, Ren J, Reiter RJ, Chen Y (2018b) Protective role of melatonin in cardiac ischemia-reperfusion injury: from thogenesis to targeted therapy. J Pineal Res 64. doi:https://doi org/10.1111/ jpi.12471

Zhou H, Shi C, Hu S, Zhu H, Ren J, Chen Y (2018c) BI1 is cia.ed with microvascular protection in cardiac ische ia reperfusio, njury via repressing Syk-Nox2-Drp1-mitochendn fission athways. Angiogenesis 21:599-615. https://d ci.org/10.1 7/s:0456-0189611-z

Zhou H, Wang J, Zhu P, Hu S, Ren J (2 8d) Ripk 3 regulates cardiac microvascular reperfusion ini the $f \mathrm{r}^{\mathrm{r}} 3 \mathrm{R}$-dependent calcium overload, XO-mediate exic. e stress and F-action/filopodiabased cellular migratio Cell Sign 1 5:12-22. https://doi.org/10. 1016/j.cellsig.2018.C .02

Zhou H, Wang J, Zhu P Zhu H, ns, Hu S, Ren J, Chen Y (2018e) NR4A1 aggra ate ce cardias microvascular ischemia reperfusion injury thro ${ }_{e}$ up moting Mff-req d mitochondrial fission by CK2alpha. Basic Res Cardi 1113:23. ht. //doi.org/10.1007/s00395-018-0682-1

Zhou H, Yue $\rightarrow$ J, Ma Q, Chen Y (2018f) Melatonin therapy for diabetic car 1omyopathy: a mechanism involving Sykmitochon drial complex I-SERCA pathway. Cell Signal 47:88-100. tps://do1.org/10.1016/j.cellsig.2018.03.012

Zhou Zhu P, Wang J, Zhu H, Ren J, Chen Y (2018g) Pathogenesis of cdiac ischemia reperfusion injury is associated with CK2alphadisturbed mitochondrial homeostasis via suppression of FUNDC1related mitophagy. Cell Death Differ 25:1080-1093. https://doi.org/ 10.1038/s41418-018-0086-7

Zhu H, Jin Q, Li Y, Ma Q, Wang J, Li D, Zhou H, Chen Y (2018a) Melatonin protected cardiac microvascular endothelial cells against oxidative stress injury via suppression of IP3R- $[\mathrm{Ca}(2+)] \mathrm{c} / \mathrm{VDAC}-$ $[\mathrm{Ca}(2+)] \mathrm{m}$ axis by activation of MAPK/ERK signaling pathway. Cell Stress Chaperones 23:101-113. https://doi.org/10.1007/ s12192-017-0827-4

Zhu P, Hu S, Jin Q, Li D, Tian F, Toan S, Li Y, Zhou H, Chen Y (2018b) Ripk3 promotes ER stress-induced necroptosis in cardiac IR injury: a mechanism involving calcium overload/XO/ROS/mPTP pathway. Redox Biol 16:157-168. https://doi.org/10.1016/j.redox.2018.02. 019 